\title{
The role of air pollution and lung function in cognitive impairment
}

\author{
Anke Hüls ${ }^{1}$, Andrea Vierkötter ${ }^{1}$, Dorothea Sugiri ${ }^{1}$, Michael J. Abramson ${ }^{2}$, \\ Ulrich Ranft ${ }^{1}$, Ursula Krämer ${ }^{1}$ and Tamara Schikowski ${ }^{1}$
}

Affiliations: ${ }^{1}$ IUF-Leibniz Research Institute for Environmental Medicine, Düsseldorf, Germany. ${ }^{2}$ School of Public Health and Preventive Medicine, Monash University, Melbourne, Australia.

Correspondence: Tamara Schikowski, Auf'm Hennekamp 50, 40225 Düsseldorf, Germany.

E-mail: tamara.schikowskidiuf-duesseldorf.de

@ERSpublications

Lung function predicts later cognitive function and partially mediates air pollution effects on cognitive function http://ow.ly/K7GH30hoj5X

Cite this article as: Hüls A, Vierkötter A, Sugiri D, et al. The role of air pollution and lung function in cognitive impairment. Eur Respir J 2018; 51: 1701963 [https://doi.org/10.1183/13993003.01963-2017].

ABSTRACT Air pollution has been associated with impaired lung and cognitive function, especially impairment in visuo-construction performance (VCP). In this article, we evaluate whether the effect of air pollution on VCP is mediated by lung function.

We used data from the SALIA cohort (baseline 1985-1994 and follow-up 2007-2010) including 587 women aged 55 years at baseline. Particulate matter (PM) and nitrogen dioxide $\left(\mathrm{NO}_{2}\right)$ exposures at baseline were estimated via land-use regression models. Lung function was characterised by averages between baseline and follow-up. We used age- and height-controlled Global Lung Initiative (GLI) z-scores of forced expiratory volume in $1 \mathrm{~s}(\mathrm{FEV} 1)$, forced vital capacity (FVC) and FEV1/FVC. VCP was assessed at follow-up with the CERAD-Plus neuropsychological test battery and causal mediation analysis was conducted.

An increase of one interquartile range in FEV1 and FVC was positively associated with VCP ( $\beta=0.18$ (95\% CI $0.02-0.34$ ) and $\beta=0.23$ (95\% CI $0.07-0.39$ ), respectively). The proportion of the association between $\mathrm{NO}_{2}$ on VCP mediated by FEV1 was $6.2 \%$ and this was higher in never smokers (7.2\%) and noncarriers of the $A P O E-\varepsilon 4$ allele (11.2\%). However, none of the mediations were statistically significant.

In conclusion, air pollution associated VCP was partially mediated by lung function. Further studies on the mechanisms underlying this pathway are required to develop new strategies to prevent air pollution induced cognitive impairment.

This article has supplementary material available from erj.ersjournals.com

Received: Sept 262017 | Accepted after revision: Dec 192017

Support statement: This work was supported by the Deutsche Forschungsgemeinschaft (DFG; HE-4510/2-1, KR 1938/ 3-1, LU 691/4-1), the Ministry of the Environment of the state of North Rhine-Westphalia (Düsseldorf, Germany), the Federal Ministry of the Environment (Berlin, Germany), DGUV (German statutory accident assurance) VT 266.1, the European Community's Seventh Framework Program (FP7/2007-2011) under grant agreement number 211250 and the German Federal Ministry of Education and Research (BMBF). The funders had no role in study design, data collection and analysis, decision to publish, or preparation of manuscript. Funding information for this article has been deposited with the Crossref Funder Registry.

Conflict of interest: M.J. Abramson has received investigator initiated grants for unrelated research from Pfizer and Boehringer-Ingelheim, and reimbursement for congress attendance from Sanofi.

Copyright @ERS 2018 


\section{Introduction}

Ambient air pollution exposure has been linked to impaired lung function [1] and chronic obstructive pulmonary disease (COPD) in the elderly [2]. Impaired lung function has also been associated with impaired cognitive function in both adults and children [3,4]. Accordingly, cognitive decline is highly prevalent in people with impaired lung function and COPD [5, 6]. Various studies investigating the association between midlife pulmonary function and cognitive function in old age have shown that pulmonary dysfunction in midlife is associated with an increased risk of poor cognition later in life [7-9]. The influence of pulmonary function on cognitive decline may result from various factors including hypoxia, reduced neurotransmitter function, increased systemic inflammation, or a combination of these processes [10].

There is emerging epidemiological evidence of an association between exposure to air pollution and cognitive decline $[11,12]$, especially with impaired visuo-construction performance (VCP; copying geometrical figures) [13]. Epidemiological studies showing a relationship between distance to major roads and cognitive decline suggest that particles from traffic sources can, due either to their size or composition, have detrimental effects on cognition $[14,15]$.

However, while the associations between respiratory health and cognitive function are well established, the relationships between air pollution, impaired lung function and cognitive decline remain unclear. Air pollution and reduced pulmonary function also inflict high oxidative stress on the body [16] and hence can potentially accelerate age-related changes in the brain. It is possible that air pollution induced impaired lung function causes changes in the central nervous system (CNS) through processes such as vascular diseases resulting from inflammation, impaired fibrinolytic activity, or oxidative stress and other cardiovascular risk factors [4, 17]. A common approach to investigating such a causal pathway in epidemiological studies is to use causal mediation analysis [18].

The objective of the current study was to investigate whether impaired lung function was not only a risk factor for cognitive decline but also if it mediated the association between air pollution exposure and cognitive decline. We used data from the Study on the influence of Air pollution on Lung function, Inflammation and Aging (SALIA) cohort.

\section{Methods}

\section{Study design and study population}

The SALIA study was initiated in the early 1980s by the North Rhine-Westphalia State Government as part of the Clean Air Plan to investigate the effect of air pollution exposure in women. The study population was a sample of women from the Ruhr area and two rural areas in Southern Münsterland. Between 1985 and 1994, health examinations were conducted in 4874 women who were 55 years of age at the time of their baseline investigations. These examinations included lung function measurements in 2785 women and details of the baseline investigation have been described elsewhere [19]. A follow-up examination was conducted between 2007 and 2010 [13]. Women who had lung function measured at baseline were invited in a randomised manner from the Ruhr area cities of Duisburg, Dortmund, Essen and Gelsenkirchen, as well as from the rural county of Borken. In total, 834 women participated who were then aged 70 to 80 years. The Ethical Committee of the University of Bochum approved the study. We received written informed consent from all participants.

\section{Assessment of respiratory health and pulmonary function \\ Spirometry was performed according to the American Thoracic Society (ATS)/European Respiratory Society (ERS) recommendations [20] at both investigations. Forced expiratory volume in $1 \mathrm{~s}$ (FEV1) and forced vital capacity (FVC) were measured. Three to four manoeuvres were performed under the direction of trained personnel and the values used were those where the maximal FEV1 was reached. All measuring instruments were calibrated prior to testing, the technical personnel were specially trained and a pulmonary physician reviewed all results. To control for age and height-dependency of lung function, we calculated z-scores from the Global Lung Initiative (GLI) reference values. In a previous publication, we showed that the GLI z-scores fitted cross-sectionally and longitudinally with FEV1, FVC and FEV1/FVC measured in our SALIA cohort [21]. To evaluate long term lung function during follow-up and to reduce measurement errors, we calculated the average GLI z-scores between baseline and follow-up investigation.}

\section{Assessment of cognitive function}

Participants were tested for cognitive function using the Consortium to Establish a Registry for Alzheimer's Disease (CERAD) neuropsychological test battery (Memory Clinic University Hospital, Basel, Switzerland, 2005). The CERAD-Plus test battery consists of 18 items which measured 10 subtests: 1) verbal fluency, 2) the Boston naming test, 3) phonetic fluency, 4) word list learning, 5) word list recall, 
6) word list recognition discriminability (recognising previously learned words), 7) VCP (copying geometrical figures), 8) recall (recalling previously presented figures), 9) the trail making test (A, B, B/A) and 10) the Mini-Mental State Examination (MMSE). The test battery is described in detail elsewhere [22].

Each subtest examines various cognitive functions in the brain to obtain a complete picture of an individual's cognition. The integrated standardisation programme of the German version of CERAD-Plus transformed subtest scores into normalised z-scores standardised for age and level of education (measured in years). In this publication, we focused on VCP, a subtest which has previously been associated with air pollution [13].

\section{Assessment of potential confounders}

We gathered questionnaire-based information about known risk factors. Information was collected regarding age, body mass index (BMI), socio-economic status, current and past smoking habits and passive smoking exposure at home or at work, as well as other risk factors. We classified socio-economic status into three categories at baseline using the highest school level achieved by either the woman or her husband. These were low ( $<10$ years), medium (10 years) or high ( $>10$ years). Additionally, we gathered information regarding depression by using the Centre for Epidemiologic Studies Depression Scale (CES-D) questionnaire with a cut-off of 22 points to indicate a depressive state [23].

The apolipoprotein- $\varepsilon 4$ allele $(A P O E-\varepsilon 4)$ is the most prevalent genetic risk factor for Alzheimer's disease [24]. DNA was extracted from each individual with a QIAamp DNA Mini Kit (QIAGEN, Hilden, Germany) using a standard procedure. DNA amplification and genotyping of the APOE polymorphisms rs429358 and rs7412 were performed by LCG/KBioscience (Hoddesdon, UK) using a Kompetitive Allele Specific PCR (KASP) single nucleotide polymorphism (SNP) genotyping system with an error rate of less than $0.3 \%$ to define the APOE- $\varepsilon 4$ isoform.

\section{Assessment of air pollution}

Outdoor air pollution concentrations were assessed according to the European Study of Cohorts for Air Pollution Effects (ESCAPE) protocol [25, 26]. Each participant was assigned an annual average concentration of nitrogen dioxide $\left(\mathrm{NO}_{2}\right)$ and particulate matter $(\mathrm{PM})$ at home (PM2.5 and PM10 for particulates, where PMx indicates particles with a 50\% cut-off aerodynamic diameter of $\mathrm{x} \mu \mathrm{m})$. Air pollution was monitored over 1 year (2008-2009) in the Ruhr area and in adjacent Münsterland. Three 2-week measurements were performed at 40 monitoring sites (20 sites for PM measurement), one each in cold, warm and intermediate seasons, and results were adjusted for temporal variation using a reference station which measured during the whole period. The measured concentrations were associated with the characteristics of land-use at the monitoring sites to obtain a regression equation. Data on nearby traffic, ports or industry, as well as population/household density derived from Geographic Information Systems (GIS), were included in the equations. The models reached high adjusted $\mathrm{R}^{2}$ values of 0.85 for PM2.5 mass, 0.66 for PM10 mass and 0.88 for $\mathrm{NO}_{2}$. They were applied to the home addresses of participants to get individual exposure concentrations.

To characterise long-term exposure at baseline (1985-1994) we back-extrapolated these exposure concentrations using the exact recruitment date as well as data for the year before and after. For each study participant's home address, the back-extrapolated concentration was obtained by multiplying the modelled ESCAPE annual mean concentration with the ratio between average annual concentrations as derived from a routine monitoring site for the period in the past and for the ESCAPE measurement period time, which was used as a reference [27].

The implicit assumption of proportional spatial contrasts over time was tested with data from six routine monitoring stations situated in the investigation area and covering the investigation period. The trend concordance was good ( $\mathrm{R}^{2}$ values between 0.42 and 0.84$)$.

\section{Statistical analysis}

We analysed the association of individual long-term exposure to air pollution at baseline with average lung function between baseline and follow-up and with VCP at follow-up. Next, we investigated the association between average lung function and VCP at follow-up, as well as the interaction between air pollution exposure and average lung function on VCP. We used multiple linear regression analysis throughout. Linear regression coefficients $(\beta)$ with corresponding $95 \%$ confidence intervals were estimated for increases of one interquartile range in baseline exposure or in the respective lung function parameter.

Furthermore, we analysed whether the average level of lung function between baseline and follow-up mediated the effect of air pollution exposure on VCP. Causal mediation analysis from a counterfactual perspective with possible exposure-mediator interaction was performed by using the $\mathrm{R}$ [28] package 
"mediation" [29], an approach that relies on the quasi-Bayesian Monte Carlo method based on normal approximation [30]. Using the counterfactual framework allows for definition of direct and indirect effects and a total effect as the sum of direct and indirect effects, even in models with interactions. The indirect effect refers to the effect through the mediator under study. The direct effect refers to the remaining effect that is not through the mediator [18]. The proportion of the indirect effect in the total effect was used to assess the extent to which the association between air pollution and VCP was mediated through impaired lung function as an intermediate pathway [31].

The proportion of air pollution associated VCP mediated by lung function might differ in subgroups defined by the presence of strong risk factors for impaired lung function or Alzheimer's disease. The robustness of the results considering these potential effect modifications was examined through sensitivity analyses in which we excluded smokers and $A P O E-\varepsilon 4$ carriers (strong risk factors for impaired lung function and Alzheimer's disease, respectively).

Age, height, BMI, socio-economic status, current and former smoking habits, exposure to second-hand smoke, living in an urban area versus a rural area, $A P O E-\varepsilon 4$ incidence, physical activity and depression were associated with air pollution, lung function or VCP in univariate analyses and were included as covariates in the models to adjust for potential confounding. All statistical analyses were carried out with R 3.4.1 for Windows [28].

\section{Results}

\section{Description of study participants, outcome and air pollution}

The characteristics of the study participants are described in table 1. Of the 834 women who participated in the follow-up examination, 520 had complete information about air pollution exposure, lung function at baseline and follow-up, and the covariates included in the statistical analysis. The average age of these women at the time of the baseline investigation (1985-1994) was 54.3 years and at follow-up (2007-2010)

TABLE 1 Description of the Study on the influence of Air pollution on Lung function, Inflammation and Aging (SALIA) population at baseline and at follow-up

\begin{tabular}{|c|c|c|c|}
\hline Characteristic & Baseline (1985-1994) & & Follow-up (2007-2010) \\
\hline Age years & $54.3 \pm 0.8$ & & $73.3 \pm 3.4$ \\
\hline BMI $\mathrm{kg} \cdot \mathrm{m}^{-2}$ & $26.6 \pm 4.0$ & & $27.3 \pm 4.5$ \\
\hline Height cm & $162.5 \pm 5.5$ & & $163.1 \pm 5.9$ \\
\hline \multicolumn{4}{|l|}{ Educational level $^{\#}$} \\
\hline$<10$ years & $92(17.7)$ & & 92 (17.7) \\
\hline 10 years & $246(47.3)$ & & $246(47.3)$ \\
\hline$>10$ years & $182(35.0)$ & & $182(35.0)$ \\
\hline \multicolumn{4}{|l|}{ Smoking } \\
\hline Active smoker & $56(10.8)$ & & $17(3.3)$ \\
\hline Ex-smoker & $54(10.4)$ & & 88 (16.9) \\
\hline Never smoker & $410(78.8)$ & & $415(79.8)$ \\
\hline Second-hand smoke & $245(47.1)$ & & $312(60.0)$ \\
\hline \multicolumn{4}{|l|}{ Residential area } \\
\hline Urban & $230(44.2)$ & & $230(44.2)$ \\
\hline Rural & $290(55.8)$ & & $290(55.8)$ \\
\hline$A P O E-\varepsilon 4$ carrier $^{\natural 1,+}$ & & & $151(29.0)$ \\
\hline Ever sport activity" & & & $222(42.7)$ \\
\hline Depression scale $>22^{\pi}$ & & & $18(3.5)$ \\
\hline GLI z-score for FEV 1 & $-0.2 \pm 1.0$ & & $0.2 \pm 1.0$ \\
\hline GLI z-score for FVC & $0.0 \pm 0.9$ & & $0.3 \pm 0.9$ \\
\hline GLI z-score for FEV $/$ FVC & $-0.4 \pm 0.8$ & & $-0.2 \pm 0.8$ \\
\hline Average $^{\S}$ GLI z-score for FEV 1 & & $0.0 \pm 0.9$ & \\
\hline Average $^{\S} \mathrm{GLI}$ z-score for FVC & & $0.1 \pm 0.8$ & \\
\hline Average ${ }^{\S}$ GLI z-score for FEV $/ F V C$ & & $-0.3 \pm 0.7$ & \\
\hline VCP & & & $-0.9 \pm 1.3$ \\
\hline
\end{tabular}

Data are presented as $\mathrm{n}(\%)$ or mean \pm SD. The total number of subjects is 520 . BMI: body mass index GLI: Global Lung Initiative; FEV1: forced expiratory volume in 1 s; FVC: forced vital capacity; VCP: visuo-construction performance (z-score of subtest "figure copying"). ": only assessed at baseline investigation; " : only assessed at follow-up investigation; ${ }^{+}$: carrier of at least one $\varepsilon 4$ allele; ${ }^{\S}$ : averaged between the lung function measurements at baseline investigation and follow-up investigation. 
it was 73.3 years. The majority of women had a school education of 10 or $>10$ years. Results from the CES-questionnaire indicated $3.5 \%$ of the women were depressed in the last week before the examination. The average GLI $\mathrm{z}$-score for FEV1 from the baseline and follow-up values was $0.0 \pm 0.9$ and the average $\mathrm{Z}$-score for FVC was $0.1 \pm 0.8$. The mean $\mathrm{z}$-score of the CERAD subtest (figure copying) was $-0.9 \pm 1.3$.

We compared baseline characteristics of participants with non-participants in a univariate analysis. Significant risk factors for loss to follow-up were a high BMI, a low socio-economic status, high levels of air pollution and low lung function values at baseline (see supplementary table S1). Within the follow-up sample, more women living in the rural area with lower levels of air pollution were included in the analyses $(\mathrm{n}=520)$ than those not included $(\mathrm{n}=314)$ (see supplementary table S1).

The distributions of air pollutants back-extrapolated to the baseline investigation are presented in table 2 . The median of the baseline concentration was $33.0 \mu \mathrm{g} \cdot \mathrm{m}^{-3}$ for $\mathrm{PM} 2.5,49.8 \mu \mathrm{g} \cdot \mathrm{m}^{-3}$ for PM10 and $33.5 \mu \mathrm{g} \cdot \mathrm{m}^{-3}$ for $\mathrm{NO}_{2}$.

\section{Association between air pollution and lung function}

Higher concentrations of PM10 and PM2.5 at baseline were associated with lower average z-scores for FEV1 and FEV1/FVC between baseline and follow-up (figure 1). Associations with FVC as well as associations of $\mathrm{NO}_{2}$ were not significant.

\section{Association between VCP and air pollution or lung function}

Air pollution exposure at baseline and average lung function from the baseline and follow-up values (mean GLI z-scores of FEV1 and FVC) showed an association with the follow-up test of VCP (table 3). Cognitive test performance was decreased with increasing air pollution as well as with decreasing lung function; however, there was no evidence for an association with the FEV1/FVC ratio. Interactions between air pollution and lung function on VCP were only moderate. Participants with high average levels of FVC were slightly more susceptible to air pollution-induced VCP impairment than participants with low average levels of FVC. None of these interactions (with the exception of $\mathrm{FVC}$ and $\mathrm{NO}_{2}$ ) was significant.

\section{Mediation of the association between air pollution and VCP by lung function}

The mediation analysis focused on the mediating effect of average lung function on the previously shown association between air pollution exposure and the VCP subtest (table 3). The largest mediated proportion was found for FEV1. For the association between $\mathrm{NO}_{2}$ and VCP, $6.2 \%$ was mediated by FEV1 (table 4). Mediated proportions were higher in never smokers (7.2\%) and non-APOE- $\varepsilon 4$ carriers (11.2\%); however, none of the mediations were statistically significant. Mediated proportions did not change when including an exposure-mediator interaction term. The indirect, direct and total effects resulting from the mediation analyses are summarised in supplementary tables S2-S4.

\section{Discussion}

In the present study, we showed that average lung function between middle and late adulthood was associated with the development of mild cognitive impairment later in life among elderly women who were followed for more than 20 years. We also showed that the association between air pollution and VCP was partially mediated by impaired lung function (up to $11 \%$ for non-APOE- $\varepsilon 4$ carriers).

Our study extends previous epidemiological studies which showed that pulmonary function was an independent risk factor for poor cognitive function [4, 7]. However, most of these studies used either a single lung function parameter, namely FEV1, or investigated a younger cohort. Poor respiratory function is related to a number of adverse health effects as well as mortality [32] and is associated with

TABLE 2 Distribution of air pollution concentrations back-extrapolated to baseline metrics according to European Study of Cohorts for Air Pollution Effects (ESCAPE) protocols

Exposure Concentration

\begin{tabular}{lcc}
\cline { 2 - 3 } & Median (IQR) & Distribution (min-max) \\
\hline $\mathrm{PM} 2.5 \mu \mathrm{g} \cdot \mathrm{m}^{-3}$ & $33.0(4.9)$ & $22.0-41.3$ \\
$\mathrm{PM} 10 \mu \mathrm{g} \cdot \mathrm{m}^{-3}$ & $49.8(8.0)$ & $32.2-65.1$ \\
$\mathrm{NO}_{2} \mu \mathrm{g} \cdot \mathrm{m}^{-3}$ & $33.5(13.8)$ & $20.3-84.1$
\end{tabular}

The total number of subjects is 520. IQR: interquartile range; PMx: particles with a $50 \%$ cut-off aerodynamic diameter of $\mathrm{x} \mu \mathrm{m} ; \mathrm{NO}_{2}$ : nitrogen dioxide. 


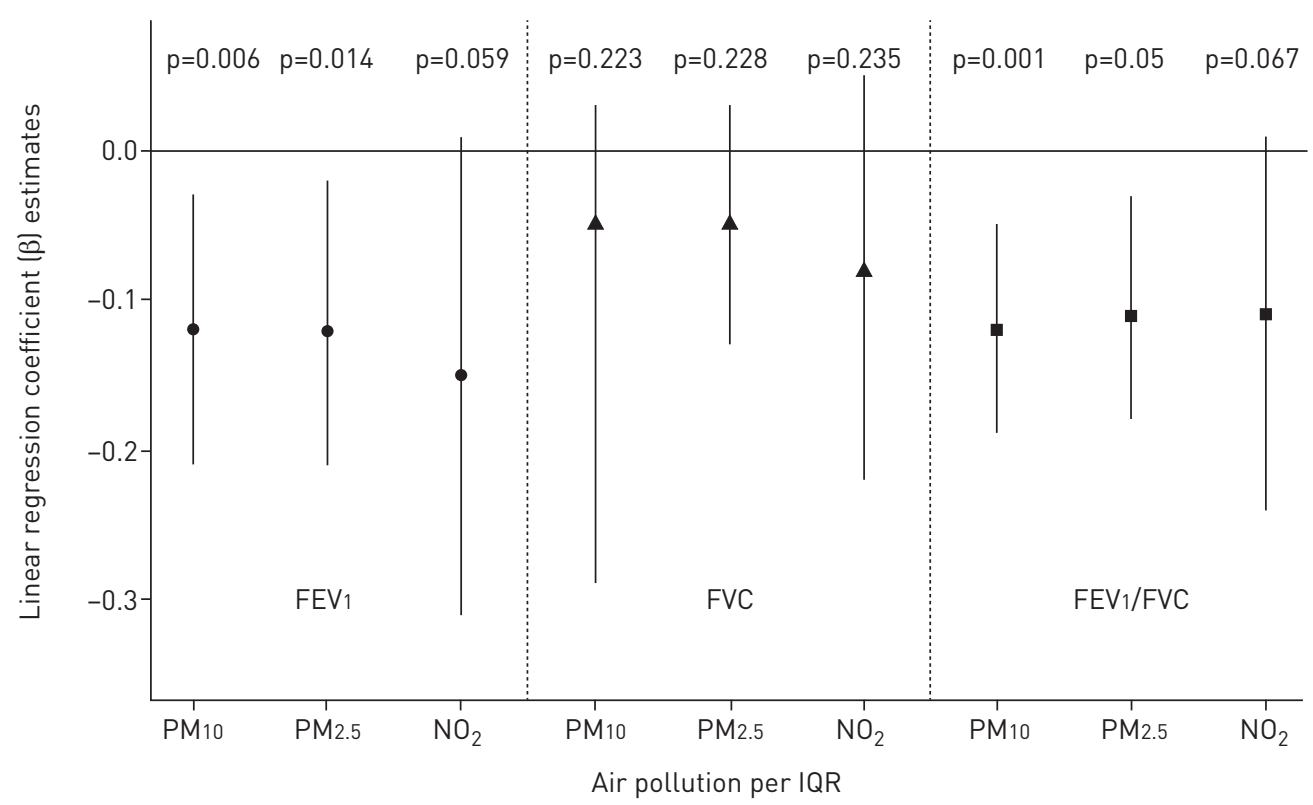

FIGURE 1 Association between air pollution exposure at baseline and average lung function between baseline and follow-up examination laverage Global Lung Initiative z-scores for forced expiratory volume in $1 \mathrm{~s}$ (FEV 1 ), forced vital capacity $(F V C)$ and $\left.F E V_{1} / F V C\right)$. Linear regression coefficients ( $\beta$ ) with corresponding $95 \%$ confidence intervals were estimated for increases of one interquartile range (IQR) in baseline exposure. All models were adjusted for age, height, body mass index, socio-economic status, current and former smoking habits, exposure to second-hand smoke, living in an urban area versus a rural area and physical activity.

TABLE 3 Association between visuo-construction performance (VCP) and air pollution at baseline, average lung function and the interaction between air pollution and lung function

\begin{tabular}{lcc} 
Exposure & $\boldsymbol{\beta}$-estimate & p-value \\
\hline Air pollution & & 0.001 \\
$\mathrm{PM}_{10}$ & $-0.25(-0.40 ;-0.11)$ & 0.005 \\
$\mathrm{PM}_{2.5}$ & $-0.21(-0.36 ;-0.06)$ & 0.030 \\
$\mathrm{NO}_{2}$ & $-0.26(-0.50 ;-0.03)$ & \\
Lung function & & 0.030 \\
$\mathrm{FEV} 1$ & $0.18(0.02 ; 0.34)$ & 0.005 \\
$\mathrm{FVC}$ & $0.23(0.07 ; 0.39)$ & 0.566 \\
$\mathrm{FEV} 1 / \mathrm{FVC}$ & $-0.04(-0.20 ; 0.11)$ & 0.381 \\
Air pollution $\times$ lung function & & 0.213 \\
$\mathrm{PM} 10 \times \mathrm{FEV} 1$ & $-0.05(-0.15 ; 0.06)$ & 0.185 \\
$\mathrm{PM}_{2.5} \times \mathrm{FEV} 1$ & $-0.07(-0.18 ; 0.04)$ & 0.142 \\
$\mathrm{NO}_{2} \times \mathrm{FEV} 1$ & $-0.10(-0.26 ; 0.05)$ & 0.090 \\
$\mathrm{PM}_{10} \times \mathrm{FVC}$ & $-0.08(-0.20 ; 0.03)$ & 0.035 \\
$\mathrm{PM}_{2.5} \times \mathrm{FVC}$ & $-0.10(-0.22 ; 0.02)$ & 0.123 \\
$\mathrm{NO}_{2} \times \mathrm{FVC}$ & $-0.18(-0.35 ;-0.01)$ & 0.208 \\
$\mathrm{PM}_{10} \times \mathrm{FEV} 1 / \mathrm{FVC}$ & $0.10(-0.03 ; 0.23)$ & 0.130 \\
$\mathrm{PM}_{2.5} \times \mathrm{FEV} 1 / \mathrm{FVC}$ & $0.09(-0.05 ; 0.23)$ & \\
$\mathrm{NO}_{2} \times \mathrm{FEV} 1 / \mathrm{FVC}$ & $0.16(-0.05 ; 0.36)$ & \\
\hline
\end{tabular}

The total number of subjects is 520 . Average lung function between baseline and follow-up examinations. VCP was measured at follow-up examination. Linear regression coefficients $(\beta)$ with corresponding $95 \%$ confidence intervals were estimated for increases of one interquartile range in air pollution or in the respective lung function parameter. All models were adjusted for age, height, body mass index, socio-economic status, current and former smoking habits, exposure to second-hand smoke, living in an urban area versus a rural area, $A P O E-\varepsilon 4$ incidence, physical activity and depression. PMx: particles with a $50 \%$ cut-off aerodynamic diameter of $\mathrm{x} \mu \mathrm{m} ; \mathrm{NO}_{2}$ : nitrogen dioxide; $\mathrm{FEV}$ : forced expiratory volume in $1 \mathrm{~s}$; FVC: forced vital capacity. 
TABLE 4 Mediation analysis in all participants, never smokers and non-APOE- $\varepsilon 4$ carriers

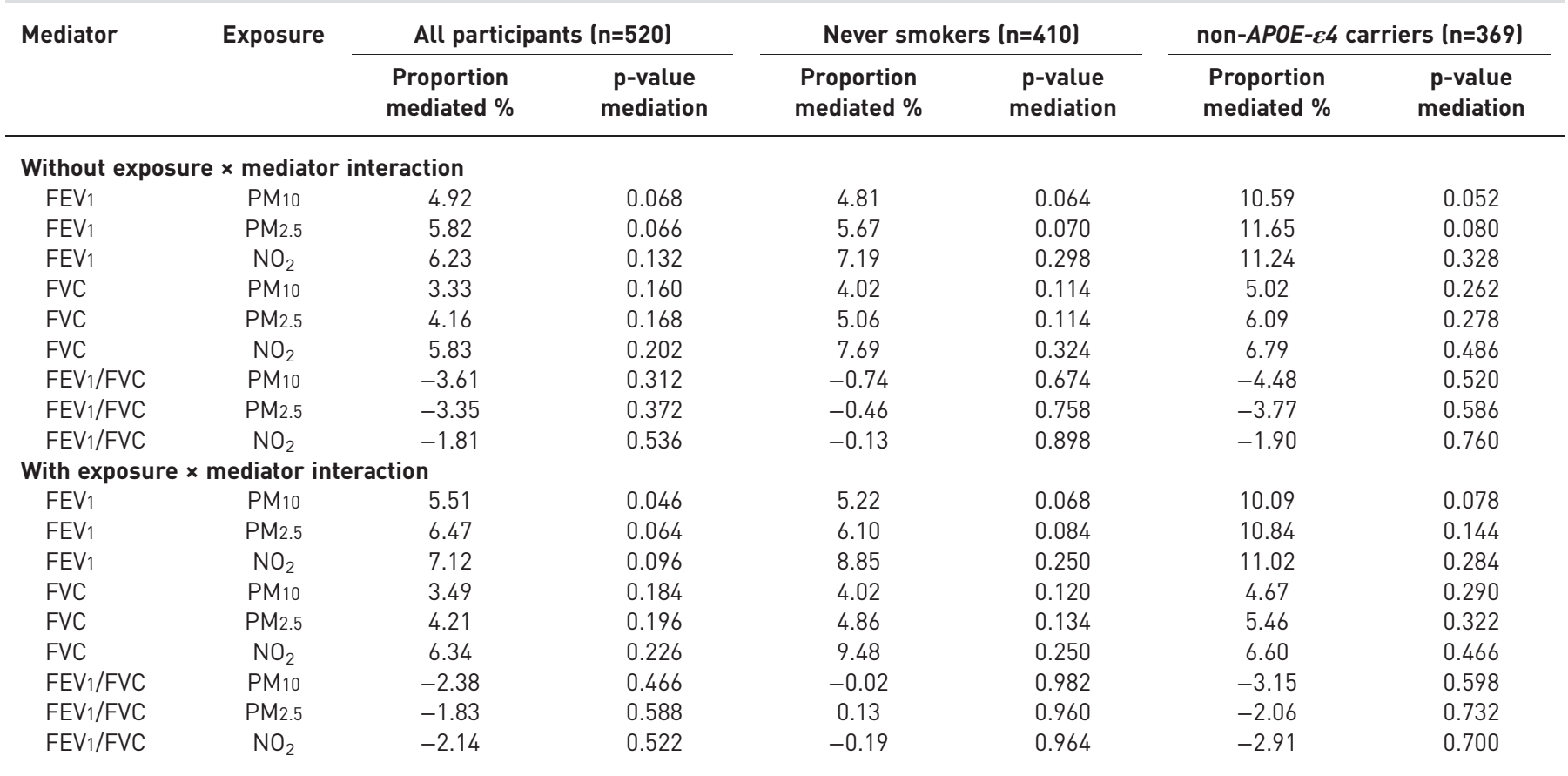

Estimated percentage of the association between air pollution exposure and visuo-construction performance (VCP; figure copying) that was mediated by a decrease in lung function. All models were adjusted for age, height, body mass index, socio-economic status, current and former smoking habits (in the analysis of all participants and in the analysis of non-APOE- $\varepsilon 4$ carriers), exposure to second-hand smoke, living in an urban area versus a rural area, $A P O E-\varepsilon 4$ incidence (in the analysis of all participants and in the analysis of never smokers), physical activity and depression. FEV1: forced expiratory volume in $1 \mathrm{~s}$; FVC: forced vital capacity; PMx: particles with a 50\% cut-off aerodynamic diameter of $\mathrm{x} \mu \mathrm{m} ; \mathrm{NO}_{2}$ : nitrogen dioxide.

socio-economic status [4] and lifestyle factors such as smoking and air pollution. However, we adjusted for all these factors and the association remained stable.

Poor pulmonary function has also been related to an increased risk of hypertension, atherosclerosis, heart disease and stroke [33,34], all of which are risk factors for the development of mild cognitive impairment and have been associated with air pollution [11,35]. A possible biological explanation for the association between impaired lung function and cognitive decline is that impaired pulmonary health can have a detrimental effect on cognitive function later in life through hypoxia and oxidative damage through systemic inflammation. It has been postulated that hypoxia impairs the metabolism of the central neurotransmitters [36]. Chronic undersupply of oxygen to the brain may cause oxidative stress and defective adenosine triphosphate production [7]. However, this explanation might only be plausible for individuals with severe lung impairment and diseases such as COPD [37]. It has been suggested that lung and cognitive function operate under common regulatory processes. Respiratory and cardiovascular control systems require the integrity of brain structures at many levels of the neuraxis [38].

Our mediation analysis suggested that only a small part of the association between air pollution and VCP was mediated by average lung function ( $6 \%$ for $\mathrm{NO}_{2}, \mathrm{FEV} 1$ and $\left.\mathrm{VCP}\right)$. The mediated proportion was slightly higher in never smokers ( $7 \%$ for $\mathrm{NO}_{2}, \mathrm{FEV} 1$ and $\left.\mathrm{VCP}\right)$ and non-APOE- $\varepsilon 4$ carriers $\left(11 \%\right.$ for $\mathrm{NO}_{2}$, FEV1 and VCP), indicating that after controlling for residual confounding and effect modifications, the mediated proportion increased. One explanation for the small part that was mediated by impaired lung function might be that spirometric measurements are only a rough proxy for lung inflammation and VCP only covers a small aspect of cognitive impairment.

Various pathways have been discussed as to how air pollution can damage the brain. Data from controlled animal studies suggest that PM can infiltrate the brain via the circulatory system [39] or translocate via the olfactory nerve [40]. Our findings support the hypothesis that at least a portion of the particles might infiltrate the brain via the circulatory system. However, the major part of the association between air pollution and VCP could not be explained by air pollution induced lung function impairment. 


\section{Strengths and limitations}

The strength of our study was the long follow-up period and the availability of repeated lung function measurements as well as a range of potential confounders on which information was collected over a period of time. Furthermore, air pollution exposures were assessed by using state of the art air pollution modelling gained from the ESCAPE campaign in 2009. In addition, we used the most recent spirometric reference values (GLI z-scores) to control for age- and height-dependencies and conducted a prevailing approach for causal mediation analysis allowing an interaction term between exposure and mediator [31]. Furthermore, our long-term cohort study enabled us to consider the chronological order of exposure, mediating event and outcome, which makes our findings more reliable than using only a cross-sectional design.

One limitation of our study was the cross-sectional investigation of cognitive function. It is possible that women with a severe cognitive impairment also performed worse in the lung function testing at follow-up due to a comprehension problem. However, since we evaluated average lung function measurements between baseline and follow-up, this would only have a small impact on our findings. Furthermore, the women who were lost to follow-up were less well educated, smoked more heavily, were exposed to higher levels of air pollution and their respiratory health was worse than those who did participate. These factors have already been shown to be predictors for cardiovascular mortality in the SALIA cohort [19] and this could have led to non-responder bias in the prevalence data. Additionally, there might be some non-responder bias in the air pollution effect and in our mediation analysis. Since air pollution levels in the analysed sample were lower than in the whole baseline sample, the effects of air pollution might have been underestimated in our study. Furthermore, our analysed sample included fewer smokers than the baseline sample and, given that the mediation effect was more pronounced in non-smokers, it might be stronger in our analysed sample than it would have been in the whole baseline sample.

Another limitation of our study is the strong set of assumptions in the causal mediation analysis. This analysis assumes no unmeasured confounding of the treatment-mediator relationship [31]. We considered all potential confounders available in our study sample but we cannot totally exclude the possibility of unmeasured confounding. Furthermore, the sample size of our study population was relatively small, which could reduce the ability to detect significant mediating effects. In this regard, our findings need to be replicated in other cohorts.

\section{Conclusions}

Our study provides indications about the mechanisms underlying the association between air pollution and cognitive decline-an association that is partly mediated by impaired lung function. We found that lung function throughout adulthood and later in life was an important predictor for the development of mild cognitive impairment in the elderly. It thus appears that maintenance of good lung function through adulthood is important for healthy brain ageing.

\section{Acknowledgements}

We thank all study members and staff involved in data collection in each cohort and also the respective funding bodies for SALIA. Study directorate: R. Dolgner, U. Krämer, U. Ranft, T. Schikowski, A. Vierkötter. Scientific team at baseline: A.W. Schlipköter, M.S. Islam, A. Brockhaus, H. Idel, R. Stiller-Winkler, W. Hadnagy, T. Eikmann. Scientific team at follow-up: D. Sugiri, A. Hüls, B. Pesch, A. Hartwig, H. Käfferlein, V. Harth, T. Brüning, T. Weiss. Study nurses: G. Seitner-Sorge, V. Jäger, G. Petczelies, I. Podolski, T. Hering, M. Goseberg. Administrative team: B. Schulten, S. Stolz. During the last decades many scientists, study nurses and laboratories were involved in conducting the study. We are most grateful for all the women from the Ruhr area and Borken who participated in the study over decades and the local Health Departments for organising the study.

\section{References}

1 Adam M, Schikowski T, Carsin AE, et al. Adult lung function and long-term air pollution exposure. ESCAPE: a multicentre cohort study and meta-analysis. Eur Respir J 2015; 45: 38-50.

2 Schikowski T, Mills IC, Anderson HR, et al. Ambient air pollution: a cause of COPD? Eur Respir J 2014; 43: 250-263.

3 Suglia SF, Wright RO, Schwartz J, et al. Association between lung function and cognition among children in a prospective birth cohort study. Psychosom Med 2008; 70: 356-362.

4 Richards M, Strachan D, Hardy R, et al. Lung function and cognitive ability in a longitudinal birth cohort study. Psychosom Med 2005; 67: 602-608.

5 Hung WW, Wisnivesky JP, Siu AL, et al. Cognitive decline among patients with chronic obstructive pulmonary disease. Am J Respir Crit Care Med 2009; 180: 134-137.

6 Dodd JW, Getov SV, Jones PW. Cognitive function in COPD. Eur Respir J 2010; 35: 913-922.

7 Guo X, Waern M, Sjögren K, et al. Midlife respiratory function and incidence of Alzheimer's disease: a 29-year longitudinal study in women. Neurobiol Aging 2007; 28: 343-350.

8 Giltay EJ, Nissinen A, Giampaoli S, et al. Apolipoprotein E genotype modifies the association between midlife lung function and cognitive function in old age. Dement Geriatr Cogn Disord 2009; 28: 433-441.

9 Dodd JW. Lung disease as a determinant of cognitive decline and dementia. Alzheimers Res Ther 2015; 7: 32. 
10 Finkel D, Reynolds CA, Emery CF, et al. Genetic and environmental variation in lung function drives subsequent variation in aging of fluid intelligence. Behav Genet 2013; 43: 274-285.

11 Clifford A, Lang L, Chen R, et al. Exposure to air pollution and cognitive functioning across the life course-a systematic literature review. Environ Res 2016; 147: 383-398.

12 Tzivian L, Dlugaj M, Winkler A, et al. Long-term air pollution and traffic noise exposures and mild cognitive impairment in older adults: a cross-sectional analysis of the Heinz Nixdorf recall study. Environ Health Perspect 2016; 124: 1361-1368

13 Schikowski T, Vossoughi M, Vierkotter A, et al. Association of air pollution with cognitive functions and its modification by APOE gene variants in elderly women. Environ Res 2015; 142: 10-16.

14 Ranft U, Schikowski T, Sugiri D, et al. Long-term exposure to traffic-related particulate matter impairs cognitive function in the elderly. Environ Res 2009; 109: 1004-1011.

15 Wellenius GA, Boyle LD, Coull BA, et al. Residential proximity to nearest major roadway and cognitive function in community-dwelling seniors: results from the MOBILIZE Boston Study. J Am Geriatr Soc 2012; 60: 2075-2080.

16 Schünemann HJ, Muti P, Freudenheim JL, et al. Oxidative stress and lung function. Am J Epidemiol 1997; 146: 939-948.

17 Liao D, Higgins M, Bryan NR, et al. Lower pulmonary function and cerebral subclinical abnormalities detected by MRI: the atherosclerosis risk in communities study. Chest 1999; 116: 150-156.

18 Ikram MA, VanderWeele TJ. A proposed clinical and biological interpretation of mediated interaction. Eur J Epidemiol 2015; 30: 1115-1118.

19 Schikowski T, Sugiri D, Ranft U, et al. Does respiratory health contribute to the effects of long-term air pollution exposure on cardiovascular mortality? Respir Res 2007; 8: 20.

20 Miller MR, Hankinson J, Brusasco V, et al. Standardisation of spirometry. Eur Respir J 2005; 26: 319-338.

21 Hüls A, Krämer U, Stolz S, et al. Applicability of the global lung initiative 2012 reference values for spirometry for longitudinal data of elderly women. PLoS One 2016; 11: e0157569.

22 Karrasch M, Laatu S, Ellfolk U, et al. Education-corrected CERAD identifies MCI and dementia in Parkinson's disease. Acta Neurol Scand 2015; 131: 219-224.

23 National Collaborating Centre for Mental Health (UK). Depression: the treatment and management of depression in adults (updated edition). Leicester, British Psychological Society, 2010.

24 Liu C-C, Liu C-C, Kanekiyo T, et al. Apolipoprotein E and Alzheimer's disease: risk, mechanisms and therapy. Nat Rev Neurol 2013; 9: 106-118.

25 Eeftens M, Beelen R, de Hoogh $\mathrm{K}$, et al. Development of land use regression models for $\mathrm{PM}(2.5), \operatorname{PM}(2.5)$ absorbance, $\mathrm{PM}(10)$ and $\mathrm{PM}($ coarse) in 20 European study areas; results of the ESCAPE project. Environ Sci Technol 2012; 46: 11195-11205.

26 Beelen $\mathrm{R}$, Hoek G, Vienneau $\mathrm{D}$, et al. Development of $\mathrm{NO}_{2}$ and $\mathrm{NO}_{\mathrm{x}}$ land use regression models for estimating air pollution exposure in 36 study areas in Europe-the ESCAPE project. Atmos Environ 2013; 72: 10-23.

27 The ESCAPE Project. Procedure for extrapolation back in time. Utrecht, The ESCAPE Project, 2012. www. escapeproject.eu/manuals/Procedure_for_extrapolation_back_in_time.pdf Date last updated: January 25, 2012. Date last accessed: January 9, 2017.

28 The R Development Core Team. The R project for statistical computing. Vienna, The R Foundation, 2017. www. r-project.org/ Date last accessed: January 9, 2017.

29 Tingley D, Yamamoto T, Hirose K, et al. Mediation: R package for causal mediation analysis. J Stat Softw 2014; 59: 1-38.

30 Imai K, Keele L, Tingley D. A general approach to causal mediation analysis. Psychol Methods 2010; 15: 309-334.

31 Valeri L, Vanderweele TJ. Mediation analysis allowing for exposure-mediator interactions and causal interpretation: theoretical assumptions and implementation with SAS and SPSS macros. Psychol Methods 2013; 18: 137-150.

32 Baughman P, Marott JL, Lange P, et al. Combined effect of lung function level and decline increases morbidity and mortality risks. Eur J Epidemiol 2012; 27: 933-943.

33 Engström G, Lind P, Hedblad B, et al. Lung function and cardiovascular risk: relationship with inflammation-sensitive plasma proteins. Circulation 2002; 106: 2555-2560.

34 Truelsen T, Prescott E, Lange P, et al. Lung function and risk of fatal and non-fatal stroke. The Copenhagen city heart study. Int J Epidemiol 2001; 30: 145-151.

35 Kaufman JD, Spalt EW, Curl CL, et al. Advances in understanding air pollution and CVD. Glob Heart 2016; 11: 343-352.

36 Gibson GE, Pulsinelli W, Blass JP, et al. Brain dysfunction in mild to moderate hypoxia. Am J Med 1981; 70: $1247-1254$

37 Bobak M, Richards M, Wadsworth M. Relation between children's height and outdoor air pollution from coal-burning sources in the British 1946 birth cohort. Int Arch Occup Environ Health 2004; 77: 383-386.

38 Harper RM. The cerebral regulation of cardiovascular and respiratory functions. Semin Pediatr Neurol 1996; 3: 13-22.

39 Peters A, Veronesi B, Calderón-Garcidueñas L, et al. Translocation and potential neurological effects of fine and ultrafine particles a critical update. Part Fibre Toxicol 2006; 3: 13.

40 Oberdörster G, Sharp Z, Atudorei V, et al. Translocation of inhaled ultrafine particles to the brain. Inhal Toxicol 2004; 16: 437-445. 